\title{
Maternal recall of infant feeding events is accurate
}

\author{
Lenore J Launer, Michele R Forman, Gillian L Hundt, Batia Sarov, David Chang,
} Heinz W Berendes, Lechaim Naggan

National Institutes of Health, Bethesda, MD, USA:

Division of Prevention

Research, National

Institute of Child

Health and Human

Development

L J Laune:

$H$ W Berendes

Division of Cancer

Prevention and

Control, National

Cancer Institute

M R Forman

Ben Gurion

University of the

Negev, Beer Sheva,

Israel:

Sociology of Health

Unit, Division of

Health in the

Community, Faculty

of Health Sciences

$G$ L Hundt

Epidemiology and

Health Services

Evaluation Unit,

Center for Health

Sciences

B Sarov

Computer Data

Systems Inc,

Rockville, MD, USA

D Chang

Dr Launer's present

address: Erasmus University

Medical School, Departmen

of Epidemiology and

Biostatistics, Rotterdam,

The Netherlands.

Correspondence to: Dr Berendes,

at DPR/NICH/NIH,

EPN Rm 640, Bethesda,

MD 20892, USA

Accepted for publication July 1991

\begin{abstract}
Study objective-Retrospective infant feeding data are important to the study of child and adult health patterns. The accuracy of maternal recall of past infant feeding events was examined and specifically the infant's age when breast feeding was stopped and formula feeding and solid foods were introduced.
\end{abstract}

Design and setting-The sample consisted of Bedouin Arab women $(n=318)$ living in the Negev in Israel who were a part of a larger cohort participating in a prospective study of infant health and who were delivered of their infants between July 1 and December 15, 1981. Data from interviews conducted 12 and 18 months postpartum were compared to the standard data collected six months postpartum.

Main results-As length of recall increased there was a small increase in the mean difference, and its standard deviation, between the standard and recalled age when breast feeding was stopped and formula feeding and solid foods were started. Recall on formula feeding was less accurate than recall on solid foods and breast feeding. In particular, among those $61 \%$ reporting formula use at the six month interview, $51 \%$ did not recall introducing formula when interviewed at 18 months. The odds ratio (95\% CI) of stunting versus normal length for age for formula fed versus breast fed infants based on recall data $(O R=2 \cdot 07$; $\mathbf{9 5} \% \mathrm{CI} 0 \cdot 82-5 \cdot 22$ ) differed only slightly from those based on the standard data $(O R=2 \cdot 21$; $95 \%$ CI $0.77-6 \cdot 37)$. The accuracy of a mother's recall varied with her child's nutritional status at the time of the interview, but not with other sociodemographic, infant, or interviewer characteristics.

Conclusions-Retrospective infant feeding data based on maternal recall of events up to 18 months in the past can be used with confidence in epidemiological studies. However, data on formula feeding may not be as accurate as data on breast feeding and solid food feeding, and accuracy may decrease as length of recall increases.

Retrospective infant feeding data have been collected to study health patterns in children and adults, such as the morbidity effects of infant feeding patterns and the relation between amenorrhoea and lactation. ${ }^{1-4}$ Moreover, these data are becoming increasingly important as studies are undertaken on the relation between early feeding patterns and chronic disease in adulthood. 56

Retrospective data are used because they can be collected more efficiently than prospective data. However, they may not be as accurate (ie, reliable or valid) and recall error may introduce bias or imprecision into study findings. ${ }^{7}$ However, as in other areas of health research, ${ }^{8}$ relatively little is known about the quality of retrospectively collected infant feeding data that are based on maternal recall of events. Together, existing studies suggest that recall is accurate, but that accuracy differs for different types of infant food. ${ }^{9-14}$ However, these studies have been based on a restricted set of analyses or on special populations (eg, clinic patients with accessible records). Therefore their findings are of limited use to those conducting community based surveys. Furthermore, previous studies have not provided us with information about differences in recall patterns among population subgroups, which is needed to improve the overall quality of data collection and analysis. ${ }^{15}$

The purpose of this study was to examine the accuracy and correlates of maternal recall of past infant feeding events. The events were the infant's age when breast feeding stopped, and when formula milk and solid foods were introduced.

Information was gathered among Bedouin Arab women and infants living in the Negev area of Israel. These women participated in a longitudinal prospective study of infant feeding and health, which has been described in detail elsewhere. ${ }^{16}$ The Bedouin Infant Feeding Study was conducted during a period of transition from a traditional semi-nomadic lifestyle to one of planned stability with greater access to markets, hospitals, and breast milk substitutes. The study was a collaborative effort of the National Institute of Child Health and Human Development in Bethesda, Maryland and the Ben Gurion University (BGU) of the Negev in Beer Sheva, Israel.

\section{Methods}

The sample used in this study is derived from the Bedouin infant feeding study cohort of 934 women who, between July 1 and December 15, 1981 , delivered normal birthweight $(\geqslant 2500 \mathrm{~g})$ singleton infants and were in hospital for delivery for less than 10 days. This cohort included a subcohort $(n=391)$ of women who were followed six, 12 , and 18 months postpartum and who are the subject of this analysis. The 391 women in the subcohort did not differ in age or parity from the women in the larger cohort, although their husbands had a slightly lower level of educational 
Table I Demographic characteristics of the Bedouin Arab women included in the analysis $(n=318)$

Table II Test-retest questions about the infant's age when a feeding practice was changed

Table III The definition of agreement groups used to assess validity of maternal recall

Table IV Distribution of infant feeding patterns at infant feeding patterns at
the six month interview attainment. Among the 391 women, the feeding history obtained at the sixth month interview was missing in 15, and another 58 were not followed up at both the 12 and the 18 month interviews. The women with missing data, excluded from this analysis, did not differ in any of the demographic characteristics shown in table I for the 318 women included in the analysis.

\begin{tabular}{lc}
\hline Characteristic & $\%$ \\
\hline $\begin{array}{l}\text { Type of settlement } \\
\text { established } \\
\text { transitional }\end{array}$ & $39 \cdot 9$ \\
traditional & $27 \cdot 6$ \\
Maternal age (years) & $32 \cdot 5$ \\
$<20$ & \\
$20-24$ & $10 \cdot 1$ \\
$25-29$ & $24 \cdot 6$ \\
$30-34$ & $26 \cdot 2$ \\
$\geqslant 35$ & $21 \cdot 4$ \\
Maternal parity & $17 \cdot 7$ \\
0 & \\
$1-2$ & $15 \cdot 7$ \\
$\geqslant 3$ & $21 \cdot 4$ \\
Paternal education (years) & $62 \cdot 9$ \\
0 & \\
$1-8$ & $80 \cdot 5$ \\
$\geqslant 9$ & $9 \cdot 1$ \\
\hline
\end{tabular}

(1) Formula feeding: When did you start to give the baby milk from a bottle (or other utensil)?

(2) Solid foods: Does the infant eat something in addition to milk? If yes, specify which food and at what age you first milk? If yes, specif
gave it to him.

(3) Breast feeding: How old was your infant when you stopped breast feeding?

(1) Concordant group: the reca.l answer was \pm 2 weeks from the first reported age if the reported age was $\leqslant 8$ weeks, and \pm 1 first reported age if the reported age was $\leqslant 8$

(2) Early recall group: the recalled age was less than the range Early recall group: the

(3) Late recall group: the recalled age was greater than the range considered concordant

(4) Denier group: reported a change in feeding practice but in subsequent interviews did not recall the feeding change

\begin{tabular}{lcc}
\hline Feeding menu & $n$ & $\%$ \\
\hline Breast fed only & 77 & 24 \\
Breast fed plus solids & 47 & 15 \\
Breast and formula fed & 14 & 04 \\
Formula fed only & 38 & 12 \\
Formula fed plus solids & 83 & 26 \\
Breast and formula fed plus solids & 59 & 19 \\
Total & 318 & 100 \\
\hline
\end{tabular}

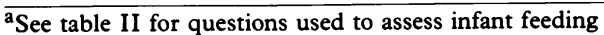

pattern breast feeding up to the six month interview

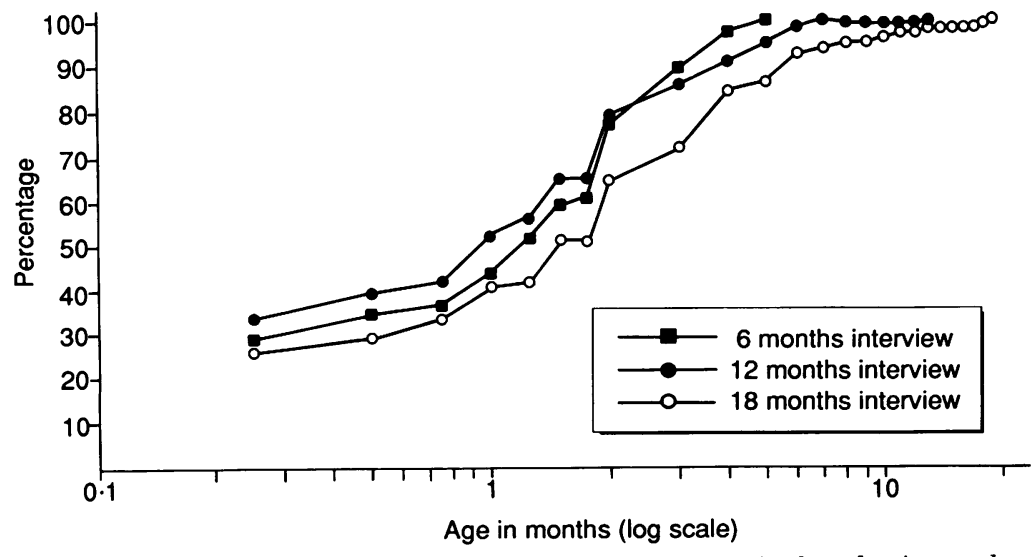

Cumulative frequency distribution of standard responses (obtained at the six month interview) and recall responses (obtained at the 12 and 18 month follow up interviews) of Bedouin Arab women asked the age when they introduced formula milk to their infant
Eleven trained Arab female interviewers from the BGU conducted the home interviews. The pretested questionnaires included items on sociodemographic, maternal, and infant health characteristics. At each of the three interviews, the same questions were asked about the infant's age at which each of the three feeding practices was changed (table II). Responses to these latter questions were recorded in weeks up to eight weeks of age and in months thereafter.

The accuracy of maternal recall was assessed by comparing the answer given by the mother at the six month interview (the standard) to her subsequent responses to the same questions on infant feeding asked at the 12 and 18 month follow up interviews. The six month data were chosen as the standard because of their high face validity. ${ }^{17}$ The standard and recalled responses were compared using: (a) cumulative frequency distributions; (b) pairwise differences, mean (SD); and (c) proportion of agreement. ${ }^{18-20}$ For the latter, we defined four agreement groups explained in table III.

We explored the effect of recall bias on the association between the six month infant feeding pattern and growth. Feeding patterns were defined on the basis of maternal answers to the questions listed in table II. Growth is dichotomised into normal length for age versus stunting, defined as $\leqslant-2$ standard deviation units below the age and sex specific median value of length from the $\mathrm{CDC} / \mathrm{WHO}$ reference population. ${ }^{21}$ For each type of infant feeding pattern ' $x$ ' prevalent at the six month interview (table IV), the sensitivity and specificity of maternal recall were calculated following Fleiss. ${ }^{22}$

Sensitivity of maternal recall was defined as the proportion of infants reported receiving feeding pattern ' $x$ ' at the six month interview who were correctly classified into the same feeding pattern on the basis of maternal recall at the 12 month interview. Specificity was defined as the proportion of those receiving all other feeding patterns (ie, other than feeding pattern ' $x$ ') at the six month interview who were correctly classified into the other feeding patterns on the basis of maternal recall at the 12 month interview. In accordance with our definition of a concordant answer (table III), an infant was correctly classified if the mother recalled that a previously reported event happened before her infant was seven months old, and misclassified if she recalled the event as happening after the infant was seven months of age. We assumed error free classification of stunting, and infants with invalid measurements at the six month interview $(n=43)$ were excluded. ${ }^{16}$ The odds ratio and approximate $95 \%$ confidence interval ${ }^{23}$ of growth by infant feeding pattern were calculated using the six month standard and the 12 month recall data.

Differences in the distribution of agreement group by various maternal, infant, and study characteristics were tested with the $\chi^{2}$ statistic, using the Statistical Analysis Systems package. ${ }^{24}$ Significance was placed at the $p \leqslant 0.05$ level.

\section{Results}

Maternal recall of the age of formula introduction was accurate to the week (figure). The recalled 
responses regarding breast feeding and formula feeding did not cluster around a particular age, although responses on solid feeding did. At the six, 12 and 18 month interviews, 3\%,10\%, and $21 \%$, respectively, stated they introduced solid foods when the infant was six months old.

Variability in age of feeding change increased with length of recall as suggested in the figure for formula feeding, and in table $\mathrm{V}$ for all three patterns. In table $\mathrm{V}$ we see that the standard

Table $V$ Pairwise difference, mean (SD), between the age (months) of feeding change reported at the six month standard interview and the age (months) recalled at the 12 and 18 month follow up interviews

\begin{tabular}{|c|c|c|c|}
\hline Feeding change & $n$ & Mean ( $S D)$ & $p$ \\
\hline $\begin{array}{l}12 \text { month }-6 \text { month interview } \\
18 \text { month }-6 \text { month interview }\end{array}$ & $\begin{array}{c}\text { Stopped breast feeding } \\
72 \\
72\end{array}$ & $\begin{array}{ll}0.65 & (1.64) \\
0.90 & (2 \cdot 31)\end{array}$ & $\begin{array}{l}0.0012 \\
0.0014\end{array}$ \\
\hline $\begin{array}{l}12 \text { month }-6 \text { month interview } \\
18 \text { month }-6 \text { month interview }\end{array}$ & $\begin{array}{c}\text { Introduced formula } \\
155 \\
96\end{array}$ & $\begin{array}{ll}0.03 & (1 \cdot 72) \\
1 \cdot 14 & (3 \cdot 07)\end{array}$ & $\begin{array}{l}\text { NS } \\
0.0004\end{array}$ \\
\hline $\begin{array}{l}12 \text { month }-6 \text { month interview } \\
18 \text { month }-6 \text { month interview }\end{array}$ & $\begin{array}{c}\text { Introduced solid food } \\
176 \\
174\end{array}$ & $\begin{array}{ll}0.15 & (1.48) \\
0.86 & (1.77)\end{array}$ & $\begin{array}{l}\text { NS } \\
0.0001\end{array}$ \\
\hline
\end{tabular}

Table VI Validity of retest answers: the percent distribution of agreement group ${ }^{\mathrm{a}}$ by interview time

\begin{tabular}{|c|c|c|c|c|}
\hline & \multicolumn{4}{|c|}{ Agreement group } \\
\hline & Denier & Concordant & Early & Late \\
\hline $\begin{array}{l}12^{\mathrm{b}} \\
18^{\mathrm{c}} \\
12-18^{\mathrm{d}}\end{array}$ & $\begin{array}{ll} & \text { Sto } \\
0 & \\
0 & \\
0 & \end{array}$ & $\begin{array}{l}\text { breast feedin } \\
62 \\
56 \\
45\end{array}$ & $\begin{array}{c}(n=7 \\
8 \\
10 \\
4\end{array}$ & $\begin{array}{l}30 \\
34 \\
20\end{array}$ \\
\hline $\begin{array}{l}12 \\
18 \\
12-18\end{array}$ & $\begin{array}{ll} & \text { In } \\
20 & \\
51 & \\
14 & \end{array}$ & $\begin{array}{l}\text { uced formula } \\
45 \\
23 \\
13\end{array}$ & $\begin{array}{c}n=194 \\
20 \\
8 \\
5\end{array}$ & $\begin{array}{r}16 \\
19 \\
5\end{array}$ \\
\hline $\begin{array}{l}12 \\
18 \\
12-18\end{array}$ & $\begin{array}{ll} & \text { Intr } \\
7 & \\
8 & \\
2 & \end{array}$ & $\begin{array}{l}\text { ced solid foods } \\
66 \\
52 \\
37\end{array}$ & $\begin{array}{c}(n=18 \\
12 \\
7 \\
3\end{array}$ & $\begin{array}{r}15 \\
33 \\
8\end{array}$ \\
\hline
\end{tabular}

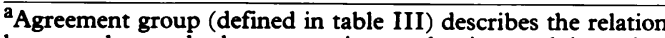
between the standard response given at the six month interview and the recalled response given at the 12 and 18 month follow up interviews

${ }^{6}$ Percent falling into the agreement group at the 12 month interview

${ }^{c}$ Percent falling into the agreement group at the 18 month interview

${ }^{\mathrm{C}}$ Percent falling into the same agreement groups at the 12 and 18 month interviews. Four of the possible 24 cells are shown; therefore, percent does not sum to 100 as in the other rows

Table VII Sensitivity and specificity of maternal recall of feeding patterns by infant nutritional status

\begin{tabular}{|c|c|c|}
\hline Pattern ' $x$ ' & Sensitivity & Specificity \\
\hline $\begin{array}{l}\text { Stunted growth }{ }^{\mathrm{a}}(\mathrm{n}=39) \\
\text { Breast fed only } \\
\text { Breast fed plus solids } \\
\text { Breast and formula fed } \\
\text { Formula fed only } \\
\text { Formula fed plus solids } \\
\text { Breast and formula fed plus solids }\end{array}$ & $\begin{array}{l}1 \\
1 \\
1 \\
1 \\
0 \cdot 84 \\
0 \cdot 66\end{array}$ & $\begin{array}{l}1 \\
0 \cdot 89 \\
1 \\
1 \\
1 \\
1\end{array}$ \\
\hline $\begin{array}{l}\text { Normal length for age }(n=236) \\
\text { Breast fed only } \\
\text { Breast fed plus solids } \\
\text { Breast and formula fed } \\
\text { Formula fed only } \\
\text { Formula fed plus solids } \\
\text { Breast and formula fed plus solids }\end{array}$ & $\begin{array}{l}1 \\
1 \\
0 \cdot 70 \\
0 \cdot 71 \\
0 \cdot 91 \\
0 \cdot 77\end{array}$ & $\begin{array}{l}0 \cdot 91 \\
0 \cdot 89 \\
1 \\
1 \\
1 \\
1\end{array}$ \\
\hline
\end{tabular}

Table VIII Odds ratio ( $95 \%$ CI) for stunting on a formula fed plus solids diet based on standard and recalled responses

\begin{tabular}{|c|c|c|c|c|c|c|c|}
\hline \multicolumn{4}{|l|}{ Standard ${ }^{\mathrm{a}}$} & \multicolumn{4}{|l|}{ Recall $^{\mathrm{b}}$} \\
\hline & $\begin{array}{l}\text { Formula } \\
\text { and solids }\end{array}$ & $\begin{array}{l}\text { Breast and } \\
\text { solids }\end{array}$ & Total & & $\begin{array}{l}\text { Formula } \\
\text { and solids }\end{array}$ & $\begin{array}{l}\text { Breast and } \\
\text { solids }\end{array}$ & Total \\
\hline $\begin{array}{l}\text { Stunted } \\
\text { Normal } \\
\text { Total }\end{array}$ & $\begin{array}{l}19 \\
72 \\
91\end{array}$ & $\begin{array}{r}5 \\
42 \\
47\end{array}$ & $\begin{array}{r}24 \\
114 \\
138\end{array}$ & $\begin{array}{l}\text { Stunted }^{c} \\
\text { Normal } \\
\text { Total }\end{array}$ & $\begin{array}{l}16 \\
56 \\
72\end{array}$ & $\begin{array}{r}8 \\
58 \\
66\end{array}$ & $\begin{array}{r}24 \\
114 \\
138\end{array}$ \\
\hline \multicolumn{4}{|c|}{$\mathrm{OR}=2 \cdot 21,95 \%$ CI $0 \cdot 77-6 \cdot 37$} & \multicolumn{4}{|c|}{$\mathrm{OR}=2.07,95 \%$ CI $0.82-5 \cdot 22$} \\
\hline
\end{tabular}

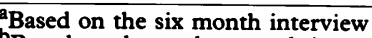

$c \leqslant-2$ standard deviation units below the CDC/WHO age and sex specific standard median 21 deviation of the paired difference between standard and recalled age increased as length of recall increased. In addition, the mean difference in paired responses significantly increased by the 18 month interview for all three feeding practices, although the magnitude of these differences was small (table V).

While the above analyses suggest that recall accuracy was similar for all three feeding practices, the analysis of agreement groups (table VI) indicates that the age of formula introduction was recalled less accurately than the other feeding changes. Women reporting on formula milk had the lowest percentage of concordant answers and the highest percentage of denial. Furthermore, proportionately fewer women were consistent across the two interviews in their responses about formula feeding than in their responses about solids and breast feeding.

The sensitivity and specificity of maternal recall by infant nutritional status at the six month interview is shown in Table VII. There was more misclassification among mothers of normal length for age infants, although this may reflect differences in sample size between the two nutritional status groups. Misclassification patterns for stunted and normal length formula fed infants differed: stunted infants fell into the breast fed and solids goups, and normal length for age infants fell into the exclusively breast fed or breast fed plus solids group. Compared to the stunted group, proportionately more normal length for age formula fed infants were misclassified into the breast fed and solids group (table VIII). However, the odds ratio for stunting on a diet of formula plus solids, based on recalled data, was only slightly reduced with slightly wider confidence intervals than those based on the standard answers.

Agreement group varied, though not significantly, by infant nutritional status. Women in the denier group had proportionately more infants who were stunted at the 12 and 18 month interviews $(26.3 \%$ and $41.2 \%$, respectively) than women in the agreement groups. Maternal factors such as age, parity, socioeconomic status, education, or type of settlement did not consistently vary by agreement group. There was also no association between agreement group and reported infant feeding practices, including age that a feeding practice was changed, reasons for introducing formula, and patterns of formula feeding. Finally, agreement was not consistently associated with interviewer.

\section{Discussion}

In these analyses we assessed the accuracy of maternal recollection of past feeding events and showed the extent to which recall error may bias the estimates of a short term effect of infant feeding practices. Unlike most other studies examining this issue, this study was conducted on a community based sample.

Our findings suggest that data on infant feeding collected retrospectively by maternal recall of events that took place less than 18 months ago are accurate. We did not find mothers preferentially recalling in multiples of three, the age breast feeding stopped, as is reported in other studies. ${ }^{25}$ 
Pairwise mean differences between the standard and recalled age of feeding change were small (range 0.03 to 1.14 months). Also, the odds ratios based on recalled data did not differ substantially from those based on the standard data. However, we did find that inaccuracy increased with length of recall, and that recall differed by feeding practice. Recall on formula feeding was less accurate than for the other feeding practices. It is likely that the reported error on formula feeding is underestimated given that the analyses were based only on the answers from women who did not deny giving formula once they had reported doing so. The high percentage of women who did provide false negative reports on formula feeding is a striking finding, not described elsewhere.

This difference in accuracy of recall by feeding practice may reflect the community's feeding patterns and the change they have undergone during the period of sedentariness. The high degree of recall accuracy on breast feeding and solid feeding may reflect entrenched norms about the age a feeding change should take place. In contrast, formula feeding was new to the community. Possibly the irregular use of this new infant food increased the likelihood that mothers did not recall using formula. For instance, they may have tried formulas, starting for some reason and then stopping for others, such as finances or because the child fell ill.

Although our results suggest the magnitude of recall error is small, the differences between the standard and recalled answer may be underestimated, since the standard we used may itself have been subject to recall error. This would be particularly so if the standard response was subject to the same sources of error as are associated with the recalled responses. However, based on our overall results, we do not think that the magnitude of the error in six month data is substantial.

The evidence that recall on formula feeding practices varied with child nutritional status warrants further investigation. Such a relation could introduce potentially confounding or misclassification bias into studies of infant feeding practices and morbidity. Besides infant status we found no evidence that maternal factors, particulars of infant feeding practices, or interviewer characteristics were related to the accuracy of maternal recall, as measured by percent agreement between responses from two interviews. Perhaps cultural factors, which are not routinely investigated in epidemiological studies, may better explain these patterns.

In conclusion, our findings suggest that infant feeding data collected within 18 months after the event can be used in community based epidemiological research. In practice, the extent to which the magnitude of the errors reported here is acceptable to other researchers depends on study objectives. ${ }^{26}$ For instance, an error in the age of formula introduction of more than a month may be more critical to studies focusing on infants less than six months of age than to studies focusing on older infants.

We hope that this study encourages other investigators to report comparable data from populations with different demographic characteristics. Further investigation into the factors that influence maternal recall about past infant feeding events will improve our capacity to study the short and long term effects of different infant feeding patterns.

The authors gratefully acknowledge the advice and support at the initiation of this project of Dr Norman Kretchmer. This was an intramural project of the National Institute of Child Health and Human Development.

1 Jason JM, Nieburg P, Marks JS. Mortality and infectious disease associated with infant-feeding. Practices in developing countries. Pediatrics 1984; 74: 702-27.

Seward JF, Serdula M. Infant feeding and infant growth. Pediatrics 1984; 74: 728-62.

3 Malloy MH, Willoughby A, Graubard B, et al. Exposure to a chloride-deficient formula during infancy: outcome at ages 9 and 10 years. Pediatrics 1990; 86: 601-10.

9 and 10 years. Pediatrics 1990; 86: 601-10. Cleland J, Scott C. World fertility survey:

Oxford: Oxford University Press, 1987 . FASEB F 1990; 4: 2605-11.

6 Davis MK, Savitz DA, Graubard BI. Infant feeding and childhood cancer. Lancet 1988; ii: 365-8.

7 Kleinbaum DG, Kupper LL, Morgenstern H. Epidemiologic research: principles and quantitative methods. New York: Van Norstrand Reinhold Books, 1982: 220-41.

8 Harlow SD, Linet MS. Agreement between questionnaire data and medical records: the evidence for accuracy of recall. Am $\mathcal{F}$ Epidemiol 1990; 129: 233-48.

9 Vobecky JS, Vobecky J, Froda S. The reliability of the maternal memory in a retrospective assessment of nutritional status. F Clin Epidemiol 1988; 41: 261-5.

10 Haaga J. Reliability of retrospective survey data on infant feeding. Demography 1988; 25: 307-14.

11 Robbins LC. The accuracy of parental recall of aspects of child development and of child rearing practices. $\mathcal{F}$ Abnorm Sociol Psychol 1963; 66: 261-70.

12 Eaton-Evans J, Dugdale AE. Recall by mothers of the birth weights and feeding of their children. Hum Nutr: Appl Nutr $1986 ; 40 \mathrm{~A}: 171-5$.

13 Goddard KE, Broder AB, Wenar C. Reliability of pediatric histories: a preliminary study. Pediatrics 1961 ; 28: 1011-8. histories: a preliminary study. Pediatrics 1961 ; 28: 1011-8.

4 Kark JD, Troya G, Friedlander Y, Slater PE, Stein Y. Validity of maternal reporting of breast feeding history and the association with blood lipids in 17 year olds in Jerusalem. F Epidemiol Comunity Health 1984; 38: 218-25. Willett WC. Nutritional
University Press, 1990.

16 Forman MR, Guptill KS, Chang DN, et al. Undernutrition among Bedouin Arab infants: the Bedouin infant feeding study. Am $\mathcal{f}$ Clin Nutr 1990; 51: 343-9.

17 Block G. A review of validations of dietary assessment methods. Am 7 Epidemiol 1982; 115: 492-505.

18 Maclure M, Willett WC. Misinterpretation and misuse of the kappa statistic. Am $\mathcal{F}$ Epidemiol 1987; 126: 161-9.

19 Fisher RA. Statistical methods for research workers. 14th ed New York: Hafner Publishing Co, 1973.

$20 \mathrm{Lee} \mathrm{J}$. Alternate approaches for quantifying aggregate and individual agreements between two methods for assessing dietary intakes. Am 7 Clin Nutr 1980; 33: 956-8.

21 WHO working group. Use and interpretation of anthropometric indicators of nutritional status. Bull WHO 1986; 64: 929-41.

22 Fleiss JL Statistical methods for rates and proportions. 2nd ed. New York: John Wiley and Sons, 1981; 188-200.

ed. New York. John epidemiology. Boston, MA: Little Brown and Company, 1986: 173.

Brown and Company, 1986: 173. SAS Institute, Inc. SAS Institute, 1985.

edition. Cary, $\mathrm{I}$. The data and their quality. In: Allan I, Dinesen B, eds. Fertility in Pakistan. A review of findings from the Pakistan Fertility Survey. Voorburg, the from the Pakistan Fertility Survey. Voorburg,

6 Bland JM, Altman DG. Statistical methods for assessing agreement between two different methods of clinical agreement between two different me. 